a chemotherapeutic agent requires active $\mathrm{NF}-\kappa \mathrm{B}$ signalling. Furthermore, the group analysed data from patients with lymphoma and identified a subpopulation in which hyperactive NF- $\mathrm{BB}$ signalling is associated with longer survival.

Genes Dev. http://dx.doi. org/10.1101/gad.17276711; http://dx.doi.org/10.1101/ gad.17620611 (2011)

\section{VIROLOGY}

\section{HIV meets its antibody match}

Antibodies that neutralize many strains of HIV seem to work by interacting with the virus's sugary coating.

Dennis Burton and Ian Wilson at the Scripps Research Institute in La Jolla, California, led a team that obtained detailed crystal structures of two broadly neutralizing antibodies bound to mannose sugars, which are present in the coat of the virus. The structure of one of the antibodies, PGT 128 (pictured), shows that it penetrates the viral coating and binds to a short strand of an HIV envelope protein called gp120, as well as to two sugars that are conserved across many HIV strains. This explains why PGT 128 can neutralize more than $70 \%$ of strains.

The results suggest that

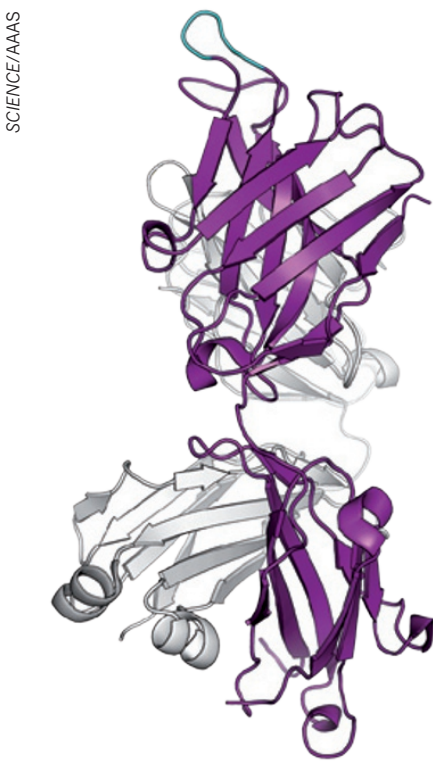

the antibodies achieve their potency by crosslinking highly accessible sections of key proteins on the surface of HIV particles. The authors say that these regions could be targets for vaccines.

Science http://dx.doi.org/

10.1126/science.1213256 (2011)

\section{AGRICULTURAL ECOLOGY}

\section{Organic farms flourish in the rain}

Organic farming is touted as a way to conserve wildlife while still producing food, but some organic farms are more biodiverse than others. This may be because of regional climatic differences.

Tatsuya Amano, now at the University of Cambridge, UK, and his colleagues examined the influence of topography and climate on the diversity of 230 rice fields in Japan with varying levels of pesticide use. The researchers measured the abundance of pest-eating Tetragnatha spiders as a proxy for biodiversity. They modelled the data and found that fields with reduced pesticide use had more spiders, with the greatest abundance in cold or wet areas.

The authors also used their model to predict which regions of Japan might benefit most from organic farming through increasing Tetragnatha numbers.

Ecol. Lett. http://dx.doi. org/10.1111/j.14610248.2011.01699.x (2011)

GANCER
links to drug target

An analysis of hundreds of breast tumours has revealed a way to target a class with poor prognosis.

Overexpression of the protein ERRa has been linked to poor clinical outcomes in patients with breast cancer. Donald McDonnell at Duke University in Durham, North Carolina, and his colleagues analysed gene expression in more than 800 breast tumours, and found that the expression

COMMUNITY CHOICE

The most viewed papers in science

\title{
Blister pack of graphene
}

\section{HIGHLY READ \\ on alp.aip.org in September}

Graphene is famous for its exotic electrical properties. But researchers at the University of Manchester, UK, have exploited the mechanical properties of these atom-thick sheets of carbon to form tiny bubbles that could one day be useful as lenses.

Konstantin Novoselov and his colleagues created graphene 'blisters' on a silicon surface. These bubbles are regularly found in large graphene flakes placed on silicon and may arise from the trapping of contaminants or air between the two materials. By applying a voltage, the researchers could control the shape of the transparent bubble. They suggest that the shifting graphene bubble could make a simple, auto-focusing lens for use in small electronic cameras such as those in mobile phones and computers.

Appl. Phys. Lett. 99, 093103 (2011)

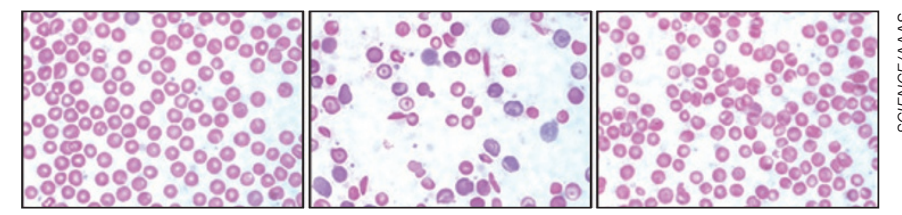

of a cluster of co-regulated genes correlated with both higher ERR $\alpha$ activity and shorter relapse-free survival. Follow-up in 17 tumour cell lines showed that tumours with increased expression of this gene cluster were also more sensitive to a compound called XCT790, which blocks ERRa signalling.

Reducing the expression of another protein, PGC1 $\beta$, an important cofactor for ERRa, also reduced ERRa signalling and cell proliferation.

Cancer Cell http://dx.doi.org/ 10.1016/j.ccr.2011.08.023 (2011)

\section{HAEMATOLOGY}

\section{A way to save sickle cells}

By knocking out a single gene, researchers have reversed sickle-cell disease in mice.

This genetic disorder results from a mutation in the adult form of the oxygen-carrying haemoglobin protein found in red blood cells, making the cells defective and causing anaemia. The fetal form is not mutated, however, so Stuart Orkin at the Dana Farber/Children's Hospital Cancer Center in Boston, Massachusetts, and his colleagues tested the effect of deleting the gene Bcl11a, which suppresses the expression of fetal haemoglobin in adults, in a mouse model of the disease.

Knockout animals had haemoglobin and red-bloodcell levels close to those of normal mice. Red blood cells from the knockout animals (pictured above, right panel) resembled those of normal controls (left) rather than those of sick mice (centre). The authors say that the BCL11A protein could be a potential, although challenging, drug target.

Science http://dx.doi. org/10.1126/science.1211053 (2011)

\section{$\rightarrow$ NATURE.COM}

For the latest research published by Nature visit:

www.nature.com/latestresearch 